\title{
Avaliação da Topografia de Superfície e Microdureza de Resinas Acrílicas e uma Resina Bisacrílica Submetidas a Diferentes Técnicas de Polimento
}

\section{Evaluación de topografía de superficie y Microdureza de resinas acrílicas y un Resina Bisacrílica Enviada a Diferentes Técnicas de pulido}

Assessment of Surface Topography and Microhardness of Acrylic Resins and a Bisacrylic Resin Submitted to Different Polishing Techniques

\author{
Eduardo Lima Santana de Ávila ${ }^{1}$ \\ Luís Felipe dos Reis Goyatá2 \\ Thamyryz Rafaela Almeida Simões ${ }^{3}$ \\ Celia Moreira Lanza ${ }^{4}$ \\ João Batista Novaes Júnior ${ }^{5}$ \\ Amália Moreno ${ }^{6}$ \\ Elissa Talma ${ }^{7}$ \\ Ivan Barreiros Doche ${ }^{8}$ \\ Frederico dos Reis Goyatá9
}

Cómo citar este artículo: Dos Reis Goyatá LF, Santana de Ávila EL, Almeida Simões TR, Moreira Lanza C, Novaes Júnior JB, Moreno A, et al. Avaliação da topografia de superfície e microdureza de resinas acrílicas e uma resina bisacrílica submetidas a diferentes técnicas de polimento. Rev Nac Odontol. 2019;15(29):1-20. doi: https://doi.org/10.16925/2357-4607.2019.02.10

Recibido: 11 de noviembre del 2017

Aprobado: 12 de abril del 2018

Publicado: 1 de julio de 2019

Artículo de investigación. https://doi.org/10.16925/2357-4607.2019.02.10

1 Faculdade de Medicina e Odontologia São Leopoldo Mandic, Campinas, Brasil ORCID: https://orcid.org/0000-0002-4192-7860

2 Faculdade de Medicina e Odontologia São Leopoldo Mandic, Campinas, Brasil ORCID: https://orcid.org/0000-0003-3692-3459

3 Universidade Federal de Minas Gerais, Belo Horizonte, Brasil ORCID: https://orcid.org/0000-0001-9003-3858

4 Universidade Federal de Minas Gerais, Belo Horizonte, Brasil ORCID: https://orcid.org/0000-0001-5893-2597

5 Universidade Federal de Minas Gerais, Belo Horizonte, Brasil ORCID: https://orcid.org/0000-0002-7079-936X

6 Universidade Federal de Minas Gerais, Belo Horizonte, Brasil ORCID: https://orcid.org/0000-0002-3474-2091

7 Universidade Federal de Minas Gerais, Belo Horizonte, Brasil ORCID: https://orcid.org/0000-0002-9853-9746

8 Universidade Federal de Minas Gerais, Belo Horizonte, Brasil ORCID: https://orcid.org/0000-0003-4335-7846

9 Universidade Federal de Minas Gerais, Belo Horizonte, Brasil ORCID: https://orcid.org/0000-0002-8540-9758

Frederico dos Reis Goyatá, Av. Pres. Antônio Carlos, 6627 Pampulha, Belo Horizonte - MG, 31270-901, Brasil. E-mail: fredgoyata05@gmail.com 


\section{Resumo}

Introdução: As resinas acrílicas são indicadas principalmente para a confecção de restaurações provisórias em prótese parcial fixa. Este trabalho tem por objetivo verificar a influência de diferentes sistemas de polimento sobre a topografia de superfície e a microdureza de três resinas acrílicas: Dencôr, Dencrilay Speed, Duralay e uma resina bisacrílica: Proviplast.

Metodologia: Foram confeccionados 140 corpos de prova com uma matriz cilíndrica de silicone de dimensões de $5 \times 2 \mathrm{~mm}$ (ISSO 4872) que foram distribuídos em quatorze grupos teste, de acordo com o polimento (n:10): ECS - escova de Carbeto de Silício, PBD - pontas de borracha impregnadas por diamante, PD - pasta diamantada e GL: aplicação do glaze. Os valores de rugosidade (Ra), Microscopia de Força Atômica (MFA) e Microdureza (Ma) foram obtidos antes e após polimento realizado com os sistemas descritos.

Resultados: Os dados obtidos no estudo foram tabulados e analisados por ANOVA e o teste " $\mathrm{t}$ " de Student $5 \%$ $(a=0,05)$. Os valores de rugosidade variaram entre 0,05 e 6,2 $\mu \mathrm{m}$ sendo que a resina bisacrílica com glaze apresentou a menor média de rugosidade $(0,05)$ e Dencrilay sem polimento apresentou o maior valor $(6,2)$. Os valores de microdureza variaram entre 23,3 e 11,6 onde o Duralay com borracha abrasiva apresentou a maior média de microdureza $(23,3)$ e Duralay com pasta o menor valor $(11,6)$. Dentre os materiais testados, a resina bisacrílica com glaze obteve o menor valor de rugosidade de superfície e a resina Duralay com borracha obteve o maior valor de microdureza.

Palavras chaves: materiais dentários, prótese dentária, polimento, odontologia.

\section{Resumen}

Introducción: las resinas acrilicas están indicadas principalmente para realizar restauraciones temporales prótesis parcial fija Este trabajo tiene como objetivo verificar la influencia de diferentes sistemas de pulido en la topografía superficial y microdureza de tres resinas acrílicas: Dencôr, Dencrilay Speed, Duralay y una resina bisacrílica: Proviplast.

Metodología: se hicieron 140 muestras con una matriz de silicona cilíndrica de dimensiones 5 × $2 \mathrm{~mm}$ (ISO 4872) que se distribuyeron en catorce grupos de prueba, según el pulido ( $n: 10)$ : ecs -cepillo de carburo de silicio, pbd- puntas de goma impregnadas con diamante, pd -pasta diamante- y GL: aplicación de esmalte. La rugosidad $(\mathrm{Ra})$, la microscopía de fuerza atómica $(\mathrm{mfa})$ se obtuvieron microdurezas $(\mathrm{Ma})$ antes y después del pulido realizado con los sistemas descritos.

Resultados: Los datos obtenidos en el estudio fueron tabulados y analizados por anova y la prueba de " $\mathrm{t}$ " de Student $5 \%(a=0.05)$. Los valores de rugosidad variaron entre 0.05 y $6.2 \mu$ m y la resina bisacrílica con esmalte presentó el promedio más bajo de rugosidad (0.05) y Dencrilay sin pulido presentó el valor más alto (6.2). El Los valores de microdureza variaron entre 23.3 y 11.6, donde Duralay con caucho abrasivo presentó el más alto microdureza promedio (23.3) y Duralay con pegar el valor más bajo (11.6). Entre los materiales probados, resina bisacrílico con esmalte obtuvo el valor de rugosidad superficial más bajo y resina Duralay con caucho obtenido el valor más alto de microdureza.

Palabras clave: materiales dentales, prótesis dentales, pulido, odontología.

\section{Abstract}

Introduction: Acrylic resins are indicated mainly for making temporary restorations fixed partial denture. This work aims to verify the influence of different polishing systems on the surface topography and microhardness of three acrylic resins: Dencôr, Dencrilay Speed, Duralay and a bisacrylic resin: Proviplast.

Methodology: 140 specimens were made with a cylindrical silicone matrix of dimensions 5 x 2 mm (ISO 4872) that were distributed in fourteen test groups, according to the polishing (n: 10): ecs - Silicon Carbide brush, pbd 
- rubber tips impregnated with diamond, pd - paste diamond and GL: application of glaze. The roughness (Ra), Atomic Force Microscopy ( $\mathrm{mfa}$ ) and Microhardness (Ma) were obtained before and after polishing performed with the described systems.

Results: The data obtained in the study were tabulated and analyzed by anova and Student's " $t$ " test $5 \%$ (a $=0.05$ ). The roughness values varied between 0.05 and $6.2 \mu \mathrm{m}$ and the bisacrylic resin with glaze presented the lowest average of roughness (0.05) and Dencrilay without polishing presented the highest value (6.2). The microhardness values varied between 23.3 and 11.6 where Duralay with abrasive rubber presented the highest average microhardness (23.3) and Duralay with paste the lowest value (11.6). Among the tested materials, resin bisacrylic with glaze obtained the lowest surface roughness value and Duralay resin with rubber obtained the highest microhardness value.

Key words: dental materials, dental prosthesis, polishing, dentistry.

\section{Introdução}

As restaurações provisórias podem ser definidas como próteses dentais temporárias, confeccionadas em resina acrílica, que pode ser termo ou autopolimerizável como afirma Barbosa et al (1). Devem prover ao paciente: estética, proteção pulpar e periodontal, proteção ao remanescente dentário, boa adaptação cervical, além de restabelecer a oclusão segundo afirmam Rutkūnas et al (2) e Braun et al (3). No entanto, elas só exercem essas funções primordiais se permanecerem durante o tempo necessário à confecção do trabalho definitivo, sem alterações significativas e não provocando alterações aos tecidos bucais a elas relacionados, de acordo com Rego et al (4) e Quirynen et al (5).

Realizar polimento nas restaurações provisórias é importante para estabelecer uma superfície lisa, promover saúde ao periodonto, conferindo maior segurança no tratamento reabilitador, além de facilitar a higiene, prevenir manchamentos e proporcionar mais conforto para o paciente, de acordo com o que afirma Serra et al (6). Uma rugosidade superficial residual pode propiciar o acúmulo de placa, que resulta em inflamação gengival, manchamento superficial e cárie secundária, conforme consideram Yap et al (7).

Desta forma, uma superfície polida minimiza o acúmulo de placa e irritação gengival, conforme citam Cardoso et al (8) e Pontes et al (9), uma vez que a adesão de microrganismos à superfície da resina acrílica, pode ser causada por um polimento inadequado, afirmação conferida por Corsalini et al (10). Cazzaniga et al (11) e Bayraktar et al (12) observaram em seus estudos que as características do material e sua composição química também desempenham um papel na formação de biofilmes. Por fim, Gharechahi et al (13) e lkeda et al (14) notaram que a colonização microbiana 
em superfícies se inicia em locais com irregularidades superficiais, onde as bactérias podem se proteger contra forças de cisalhamento hidrodinâmicas.

O estudo de Orsi et al (15) verificou que o tipo de polimento (mecânico ou químico) também pode interferir na liberação de glutaraldeído após a desinfecção química de próteses feitas em resina acrílica, um achado interessante ao pesquisar mais esferas acerca de técnicas de polimento e suas consequências.

Segundo Neisser et al (16) também se faz necessário levar em consideração que quanto maior a microdureza de superfície de uma resina acrílica maior a resistência à abrasão por escovação, sendo que, quando ocorre um desgaste na superfície da resina, a rugosidade torna-se um problema significativo, aumentando a área de contato e promovendo a retenção de placa bacteriana.

Ulusoy et al (17) infere outra informação que deve ser levada em conta: o polimento de resinas acrílicas é realizado em etapas, e uma negligência em qualquer fase do procedimento torna mais difíceis os estágios subsequentes do polimento, causando sequelas na superfície da resina acrílica.

Sen et al (18) demonstra que um dos grandes objetivos da Odontologia têm sido a pesquisa científica e clínica para o desenvolvimento de novos materiais restauradores, tanto de aplicação direta, como indireta, que reproduzam as características anatômicas e estéticas dos dentes. Esses materiais vedam adequadamente a interface dente e restauração.

Os autores Oliveira et al (19) e Barbosa et al (20) afirmam que a rugosidade superficial é uma característica importante de materiais dentários, uma vez que o valor de 0,2 $\mu$ m de rugosidade superficial ( $R a)$ é considerado o limite abaixo do qual não é esperado ocorrer aderência bacteriana, havendo assim uma direta correlação entre Ra e aderência bacteriana.

De acordo com Seabra et al (21), desta forma, o cirurgião-dentista pode contribuir para evitar o aparecimento ou recidivas de doenças periodontais e cáries com as suas orientações ao paciente, mas não pode descuidar quanto a efetivos procedimentos de acabamento e polimento em suas restaurações diretas ou indiretas.

Vários métodos de tratamento de superfície das resinas acrílicas já foram descritos e testados na literatura, conforme afirma Giacomelli et al (22). Os autores Da Costa et al (23), Antonson et al (24), Montanaro et al (25), lonescu et al (26), Santos et al (27), Liberato et al (28), Scheibe et al (29), Cakan et al (30), Rahal et al (31), Zanghellini et al (32), Gotusso (33) e Neves e Villela (34) comentam sobre algumas dessas técnicas. Entre elas: o polimento químico; o polimento utilizando disco de feltro com pedra pomes, discos e borrachas abrasivas; o polimento com materiais líquidos; imersão da resina polimerizada em monômero aquecido; pastas para polimento; e verniz over 
coat. Entretanto, alguns desses métodos ainda não são de conhecimento e prática dos cirurgiões dentistas, uma vez que necessitam de equipamentos especiais ou de etapas laboratoriais.

Considerando que existem ainda grandes discussões acerca de qual resina acrílica e qual método de polimento é mais eficaz na redução da rugosidade na superfície destes materiais, este trabalho tem como objetivo avaliar a rugosidade de superfície e microdureza de três resinas acrílicas e uma resina bisacrílica submetidas a diferentes métodos de polimento. Também, será realizada uma análise qualitativa da topografia de superfície das resinas pela microscopia de força atômica (AFM) para fins ilustrativos.

\section{Materiais e métodos}

Foram utilizadas três resinas acrílicas denominadas comercialmente como Dencôr, Duralay e Dencrilay, além de uma resina bisacrílica (Proviplast) (quadro 1)

Quadro 1. Materiais utilizados

\begin{tabular}{|c|c|c|}
\hline Nome comercial & Composição química & Fabricante \\
\hline Dencôr & $\begin{array}{l}\text { Líquido: monômero metil metacrilato, DMT, Cross- Link. } \\
\text { Pó: copolímero metil metacrilato, pigmentos org., peróxido. }\end{array}$ & Clássico, Brasil \\
\hline Duralay & $\begin{array}{l}\text { Líquido: metacrilato de metila. } \\
\text { Pó: polimetilmetacrilato, Noc particulados, } \\
\text { monômeros residuais, dialsilftalatos. }\end{array}$ & $\begin{array}{l}\text { Reliance Inc., } \\
\text { Estados Unidos }\end{array}$ \\
\hline Dencrilay & $\begin{array}{l}\text { Líquido: metilmetacrilato, EDMA (Crosslink), inibidor, } \\
\text { fluorescente, DMT. } \\
\text { Pó: polimetilmetacrilato, peróxido de benzoíla, } \\
\text { pigmentos biocompatíveis }\end{array}$ & Dencril/Vipi, Brasil \\
\hline Proviplast & $\begin{array}{l}\text { Catalisador: dióxido de silício, catalisadores e veículo; } \\
\text { Base: grupos dimetacrilatos, carga inorgânica, } \\
\text { dióxido de silício, essência, pigmentos e catalisadores. }\end{array}$ & Biodinâmica, Brasil \\
\hline
\end{tabular}

Fonte: elaboração própria

Foram confeccionados 140 corpos de prova, distribuídos aleatoriamente em quatorze grupos teste ( $n=10)$ : GI- Dencôr sem polimento; GII- Duralay sem polimento; GIIIDencrilay sem polimento; GIIV- Proviplast lixada; GV- Dencôr com Carbeto de Silício; GVI- Dencôr com pasta e feltro; GVII- Dencôr com borracha abrasiva; GVIII- Duralay com Carbeto de Silício; GIX- Duralay com pasta e feltro; GX- Duralay com borracha abrasiva; GXI- Dencrilay com Carbeto de Silício; GXII- Dencrilay com pasta e feltro; GXIII- Dencrilay com borracha abrasiva; GXIV- Proviplast com glaze. 
As amostras foram confeccionadas com o auxílio de uma matriz de silicone cilíndrica com dimensões de $5 \mathrm{~mm}$ de diâmetro e $2 \mathrm{~mm}$ de espessura (ISO 4872). As resinas acrílicas foram inseridas em único incremento com auxílio de uma seringa Centrix, sempre manipuladas pelo mesmo operador, seguindo as instruções do fabricante. E a resina bisacrílica foi inserida com auxílio de uma pistola de auto mistura fornecida pelo fabricante. Em seguida, uma placa de vidro foi pressionada sobre a matriz para promover uma uniformidade na superfície das amostras. Para finalizar, as amostras foram armazenadas em água a $37^{\circ} \mathrm{C}$ por sete dias, até a primeira análise da rugosidade de superfície.

Foi realizada uma análise inicial de rugosidade em cada resina testada e as amostras foram posicionadas individualmente em um rugosímetro SV-3000 (Mitutoyo, Suzano, Brasil) com a superfície inicialmente submetida à padronização da topografia. Para a fixação dos corpos de prova, foi utilizada cera utilidade sob uma base metálica cilíndrica. Realizaram-se três leituras paralelas com a agulha do rugosímetro para mensuração da média de rugosidade superficial ( $\mathrm{Ra}$ ) inicial. A extensão de cada leitura foi de 1,25 mm, utilizando um cut-off de 0,25 $\mu$ m e velocidade $0,1 \mathrm{~mm} / \mathrm{seg}$.

Ao término da primeira análise, as amostras foram submetidas aos métodos de polimento: escova de carbeto de silício, pasta diamantada e feltro, borracha abrasiva para as resinas acrílicas e para a resina bisacrílica, desgaste inicial com lixa de abrasiva \#600 (3M) em movimentos octogonais de 30 segundos para simular um desgaste intra-oral com pontas diamantadas finas e posterior aplicação do glaze sendo fotoativado por 30seg. A partir daí, realizaram-se a segunda análise da rugosidade de superfície seguindo os mesmos parâmetros da primeira.

Para o ensaio de microdureza, foi selecionado aleatoriamente um corpo de prova representativo de cada grupo teste. A amostra foi posicionada em um paralelômetro, objetivando eliminar qualquer variação de angulação na mensuração da microdureza Knoop. Utilizou-se o microdurômetro MVD 401 (Wilson Instruments, China) sob carga de 50 gramas, por 12 segundos. Sete mensurações de dureza foram efetuadas em cada amostra, em locais pré-determinados. As medidas obtidas (em micrometros) foram convertidas em número de dureza Knoop, por meio do software do próprio microdurômetro.

Os valores de rugosidade e microdureza das resinas testadas antes e após os métodos de polimento foram tabulados e analisados estatisticamente, por ANOVA com $0,5 \%(a=0,05)$ de significância. E para a resina bisacrílica foi utilizado o teste " $t$ " de Student. 


\section{Resultados}

Os métodos de polimento utilizados neste estudo proporcionaram uma redução estatisticamente significativa na rugosidade de superfícies para todas as resinas testadas $(p<0,0001)$ (tabela 1).

Tabela 1. Médias de rugosidade $(\mathrm{em} \mu \mathrm{m})$

\begin{tabular}{ccc}
\hline Grupos & Média & Desvio Padrão \\
\hline GI: Dencôr s/ polim. & 4,33 & 0,03 \\
\hline GII: Duralay s/ polimen. & 5,67 & 0,05 \\
\hline GIII: Dencrilay s/ polim. & 6,20 & 0,50 \\
\hline GIV: Proviplast - Lixa & 0,21 & 0,09 \\
\hline GV: Dencôr - ECS & 0,47 & 0,20 \\
\hline GVI: Dencôr - PD & 0,27 & 0,10 \\
\hline GVII: Dencôr - PBD & 0,31 & 0,16 \\
\hline GVIII: Duralay - ECS & 0,30 & 0,06 \\
\hline GIX: Duralay - PD & 0,17 & 0,11 \\
\hline GX: Duralay - PBD & 0,21 & 0,07 \\
\hline GXI: Dencrilay - ECS & 0,13 & 0,06 \\
\hline GXII: Dencrilay - PD & 0,11 & 0,10 \\
\hline GXIII: Dencrlay - PBD & 0,11 & 0,05 \\
\hline GXIV: Proviplast - Glaze & 0,05 & 0,01 \\
\hline
\end{tabular}

Fonte: elaboração própria

As resinas Dencôr e Dencrilay não apresentaram diferenças significativas $(p>0,05)$ em relação aos métodos de polimentos realizados e a resina Duralay resultou em diferença muito pouco significativa ( $p=0,0983 ; F=2,832)$ entre os polimentos, com maior redução na rugosidade de superfície com a aplicação da pasta diamantada (0,17um).

Para as resinas Dencôr $(0,27 \mu \mathrm{m})$ e Duralay $(0,17 \mu \mathrm{m})$, o uso da pasta diamantada com disco de feltro provou ser o método de polimento mais efetivo para reduzir a rugosidade de superfície das resinas referidas. Já com a resina Dencrilay $(0,11 \mu \mathrm{m})$, a borracha abrasiva teve o melhor resultado.

Quanto ao efeito dos tipos de polimento entre as três resinas, o teste ANOVA demonstrou diferenças significativas ( $p=0,0041)$ no uso da escova de carbeto de silício, outras significativas com a borracha abrasiva $(p=0,04)$ e não significativa com a pasta diamantada $(p=0,08)$. Tanto a escova de carbeto de silício $(0,13 \mu m)$ como a borracha abrasiva $(0,11 \mu \mathrm{m})$ e a pasta diamantada $(0,11 \mu \mathrm{m})$ possibilitaram uma redução expressiva na rugosidade de superfície para a resina Dencrilay. 
As resinas Dencôr, Duralay e Dencrilay demonstraram diferenças significativas $(p<0,0001)$ em relação à avaliação de todos os polimentos juntos, principalmente, entre as resinas Dencôr $(0,35 \mu \mathrm{m})$ e Dencrilay $(0,11 \mu \mathrm{m})$, o que ratifica a resina Dencrilay como uma resina que possibilita uma superfície mais lisa prevenindo a aderência bacteriana.

Em relação à resina bisacrílica, a inferência estatística com o teste " $t$ ", mostrou diferenças significativas $(p=0,0050)$ entre a aplicação do glaze $(0,05 \mu m)$ e a utilização da lixa abrasiva $(0,21 \mu \mathrm{m})$, indicando uma maior eficácia do glaze.

Considerando a microdureza, o teste ANOVA indicou que as resinas Dencôr e Dencrilay não demonstraram diferenças significativas ( $p>0,05$ ); a resina Duralay resultou em diferença significativa $(p=0,01)$ com relação aos métodos de polimento aplicados, sendo a borracha abrasiva $(23,3 \mathrm{HK} \pm 5,50)$, principalmente, comparando com o uso da pasta diamantada $(11,6 \pm 0,23)$ (tabela 2).

Tabela 2. Médias de microdureza (em HK)

\begin{tabular}{ccc}
\hline Grupos & Média & Desvio Padrão \\
\hline GI: Dencôr s/ polim. & 15,42 & 3,44 \\
\hline GII: Duralay s/ polim. & 17,12 & 5,82 \\
\hline GIII: Dencrilay s/ polim. & 17,07 & 2,60 \\
\hline GIV: Proviplast - Lixa & 13,06 & 1,15 \\
\hline GV: Dencôr - ECS & 17,70 & 3,29 \\
\hline GVI: Dencôr - PD & 13,13 & 2,11 \\
\hline GVII: Dencôr - PBD & 15,43 & 4,05 \\
\hline GVIII: Duralay - ECS & 16,33 & 2,17 \\
\hline GIX: Duralay - PD & 11,66 & 0,23 \\
\hline GX: Duralay - PBD & 23,36 & 5,50 \\
\hline GXI: Dencrilay - ECS & 16,63 & 2,57 \\
\hline GXII: Dencrilay - PD & 17,23 & 3,80 \\
\hline GXIII: Dencrlay - PBD & 17,66 & 2,54 \\
\hline GXIV: Proviplast - Glaze & 13,06 & 0,20 \\
\hline
\end{tabular}

Fonte: elaboração própria

Quanto aos resultados de microdureza entre as três resinas, o teste ANOVA demonstrou diferenças não significativas ( $p>0,05$ ) no uso de carbeto de silício, da borracha abrasiva e da pasta diamantada. Entretanto, comparando as médias, observou-se que a escova de carbeto de silício $(17,7 \mathrm{HK} \pm 3,29)$ obteve maior média na resina Dencôr, a borracha abrasiva $(23,36 \mathrm{HK} \pm 5,50)$ na resina Duralay e a pasta diamantada $(17,23 \mathrm{HK}$ $\pm 3,80)$ na resina acrílica Dencrilay. 
Eduardo Lima Santana de Ávila, Luís Felipe dos Reis Goyatá, Thamyryz Rafaela Almeida Simões, Celia Moreira Lanza, 9 João Batista Novaes Júnior, Amália Moreno, Elissa Talma, Ivan Barreiros Doche, Frederico dos Reis Goyatá

As resinas Dencôr, Duralay e Dencrilay não demostraram diferenças significativas $(p>0,05)$ em relação à avaliação da microdureza de todos os materiais testados, porém, as resinas Duralay $(17,12 \mathrm{HK})$ e Dencrilay $(17,07 \mathrm{KH})$ demonstraram ser melhores na resistência à ação física do que a Dencôr (15,42HK).

Com relação à microdureza da resina bisacrílica, o teste "t" não apontou diferenças significativas $(p=0,33)$ entre os métodos glaze e lixa.

Pela análise da topografia de superfície das resinas com a Microscopia de Força Atômica (AFM), nota-se uma conformidade com os valores médios de rugosidade encontrados nos grupos teste (figuras 1-14).

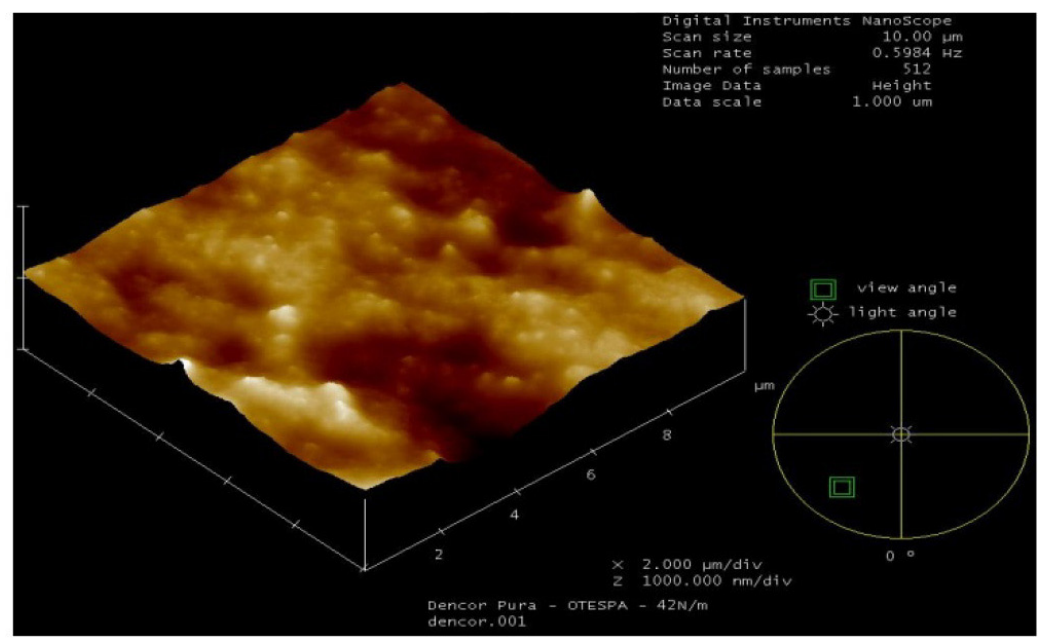

Figura 1. GI - Dencôr sem polimento Fonte: elaboração própria

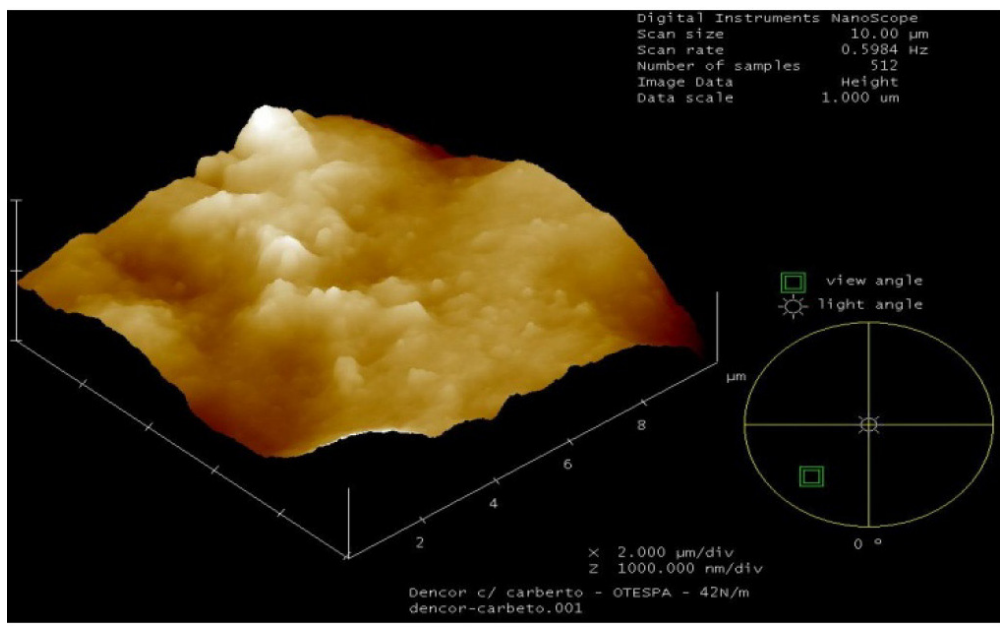

Figura 2. GV - Dencôr com Carbeto de Silício Fonte: elaboração própria 


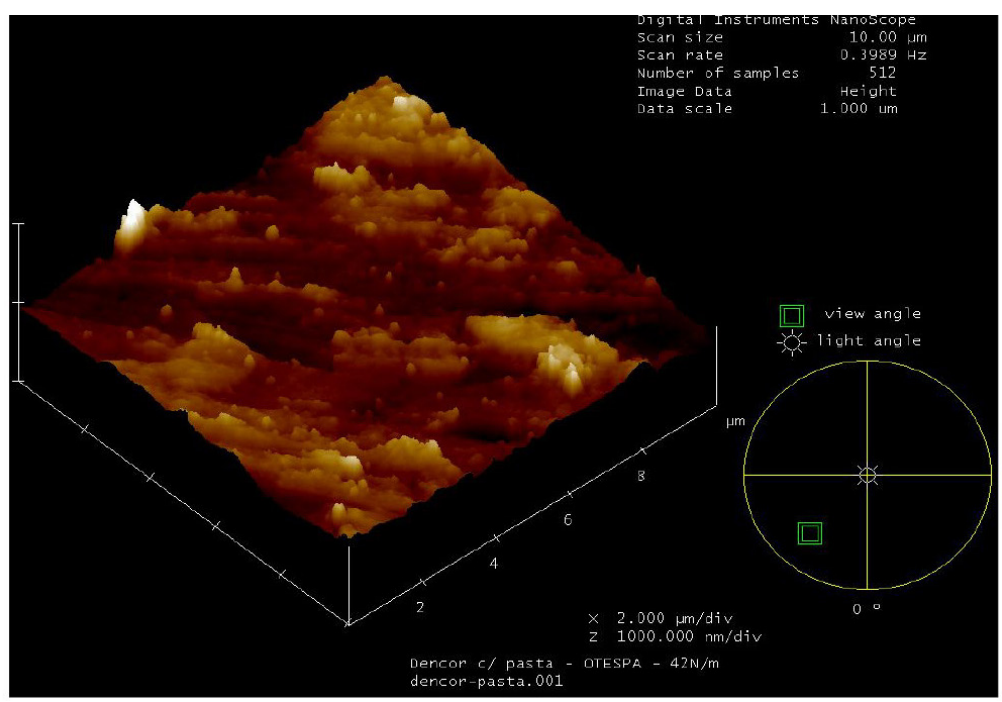

Figura 3. GVI- Dencôr com pasta e feltro Fonte: elaboração própria

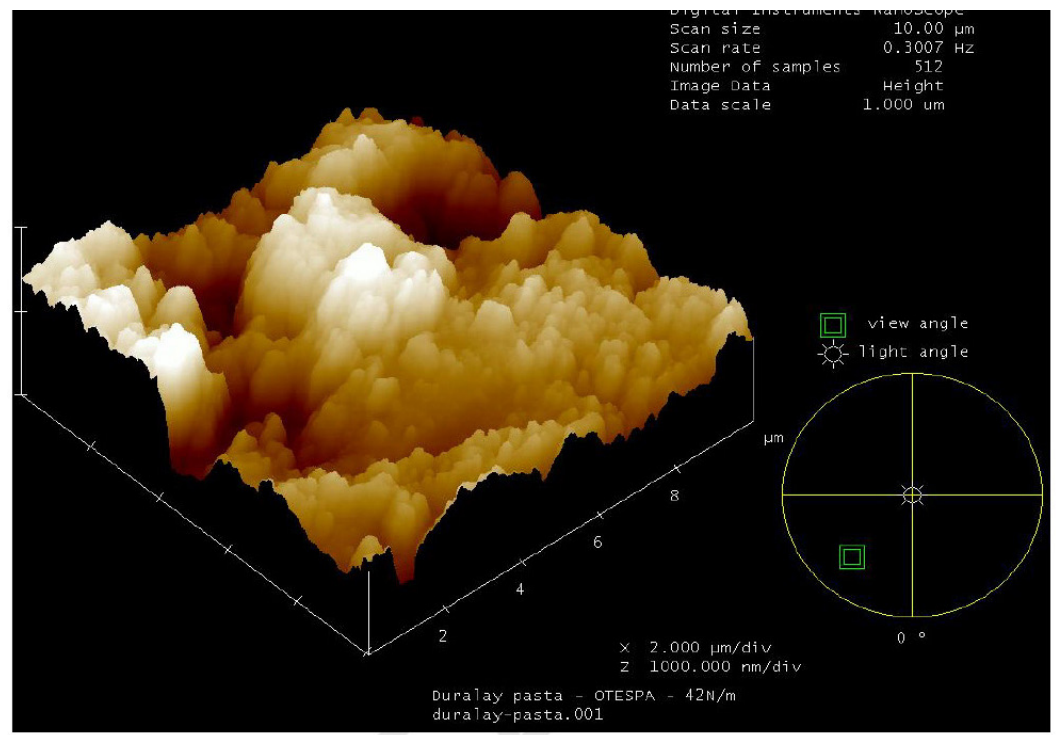

Figura 4. GVII - Dencôr com borracha abrasiva Fonte: elaboração própria 

João Batista Novaes Júnior, Amália Moreno, Elissa Talma, Ivan Barreiros Doche, Frederico dos Reis Goyatá

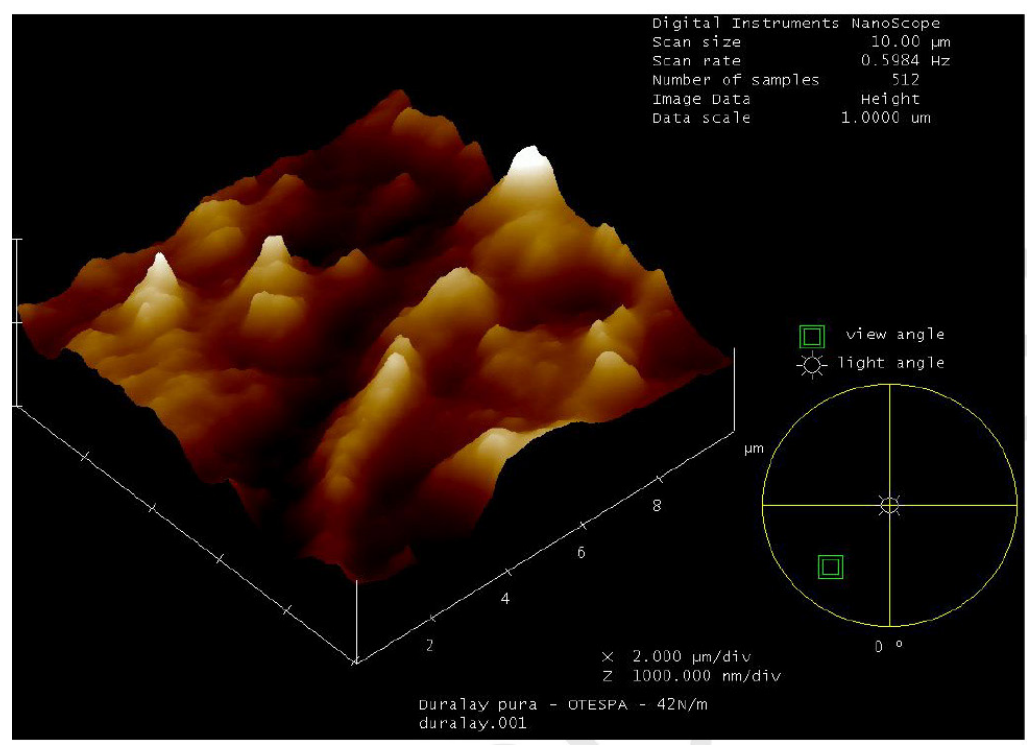

Figura 5. GII - Duralay sem polimento

Fonte: elaboração própria

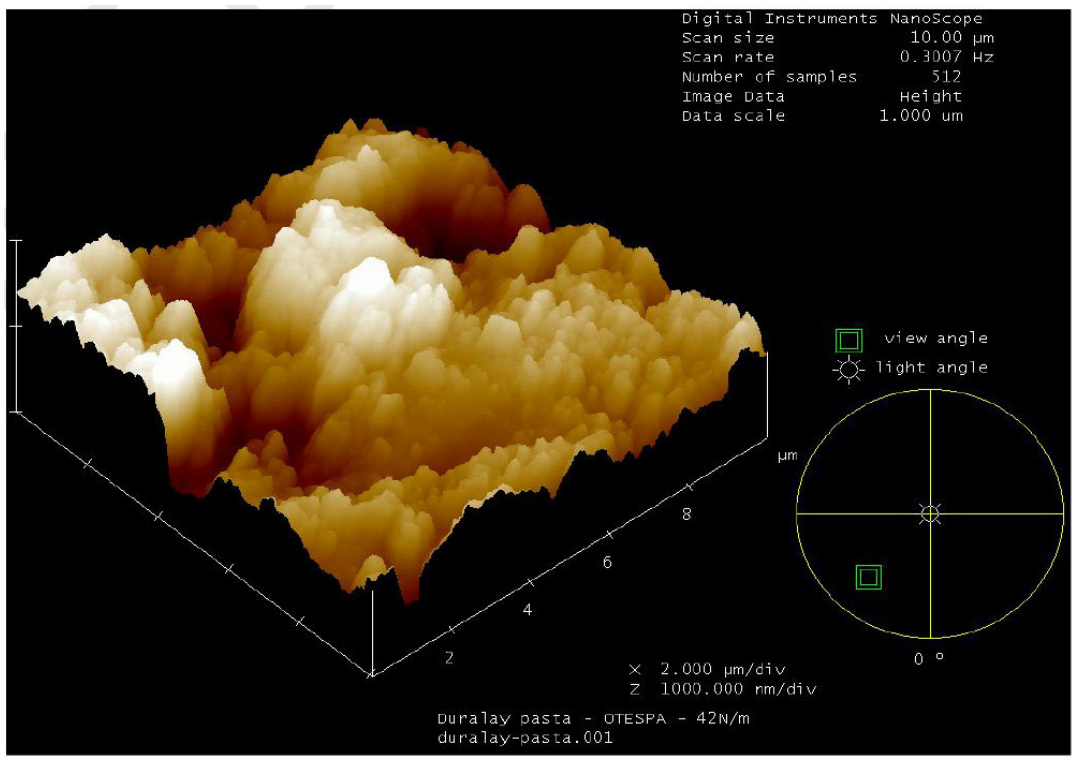

Figura 6. GVIII - Duralay com Carbeto de Silício

Fonte: elaboração própria 


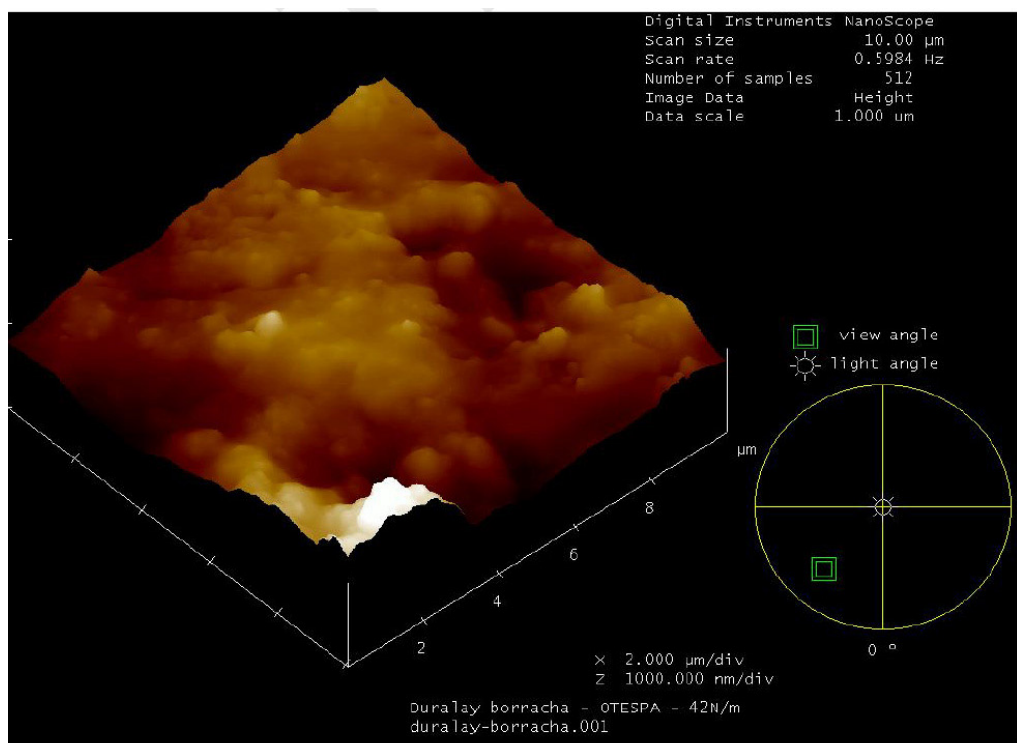

Figura 7. GIX - Duralay com pasta e feltro Fonte: elaboração própria

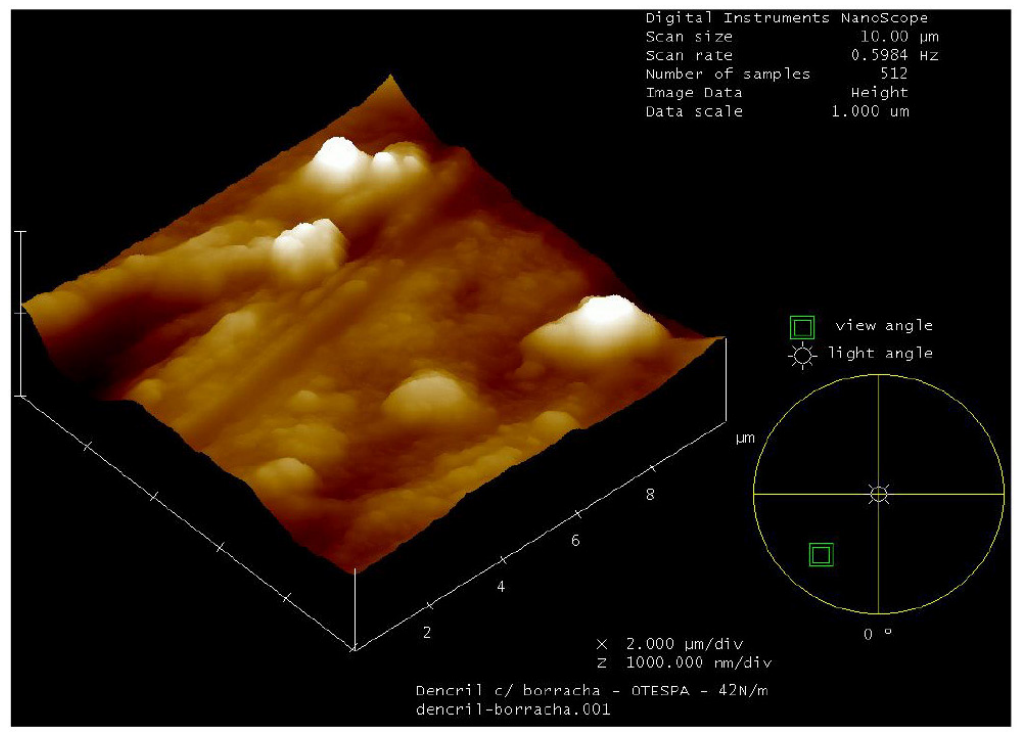

Figura 8. GX - Duralay com borracha abrasiva Fonte: elaboração própria 

João Batista Novaes Júnior, Amália Moreno, Elissa Talma, Ivan Barreiros Doche, Frederico dos Reis Goyatá

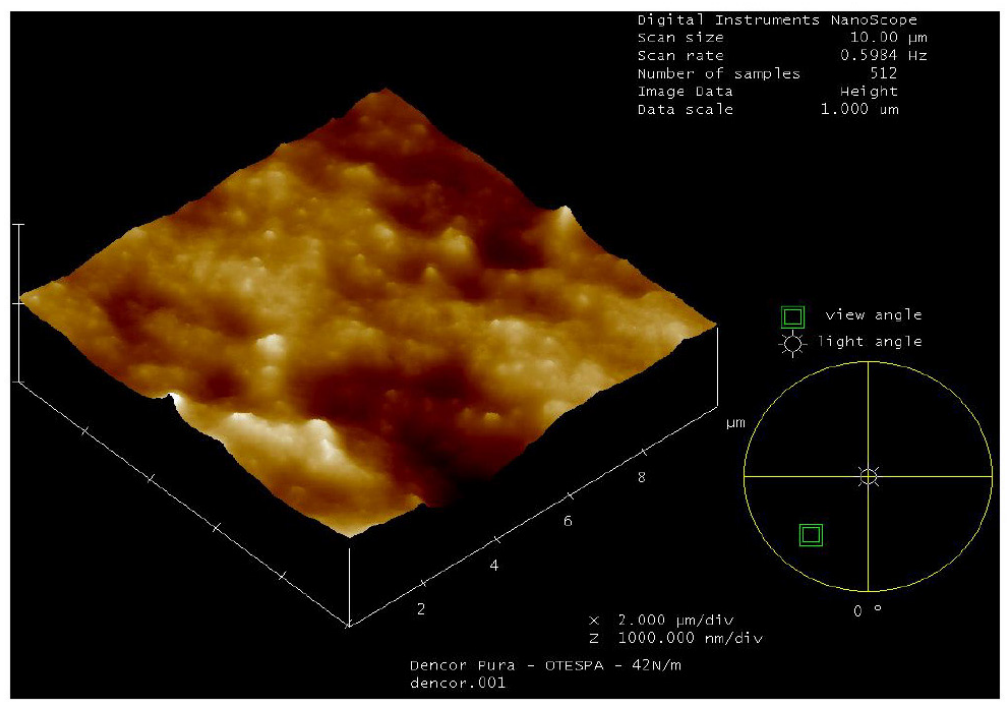

Figura 9. GIII - Dencrilay sem polimento Fonte: elaboração própria

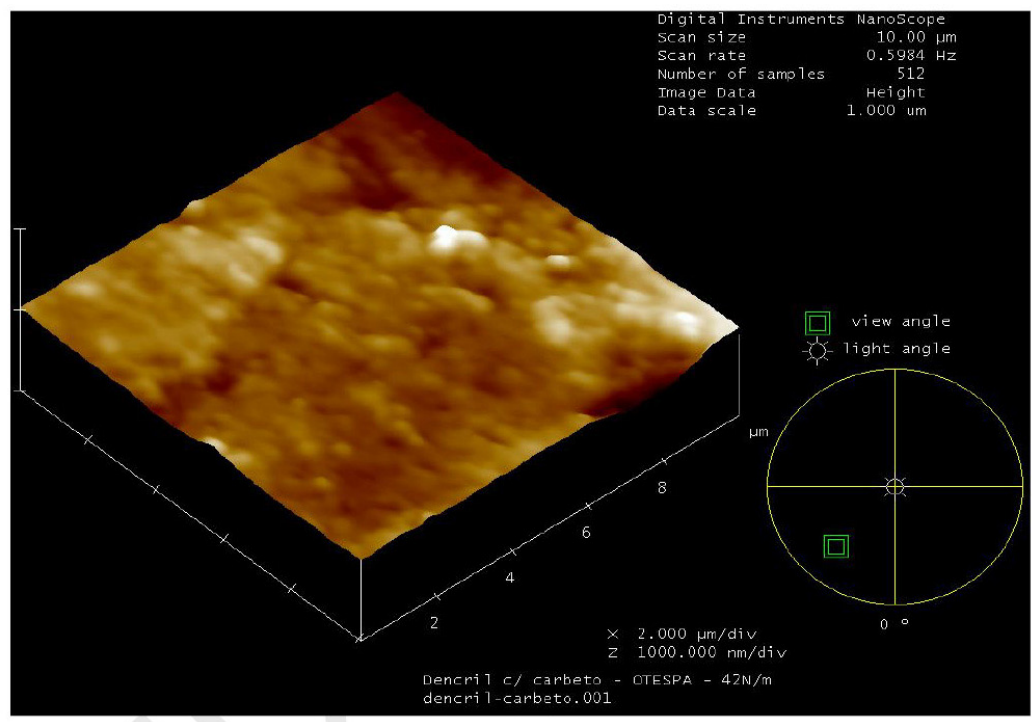

Figura 10. GXI - Dencrilay com Carbeto de Silício Fonte: elaboração própria 
14 Avaliação da Topografia de Superfície e Microdureza de Resinas Acrílicas e uma Resina Bisacrílica Submetidas a Diferentes Técnicas de Polimento

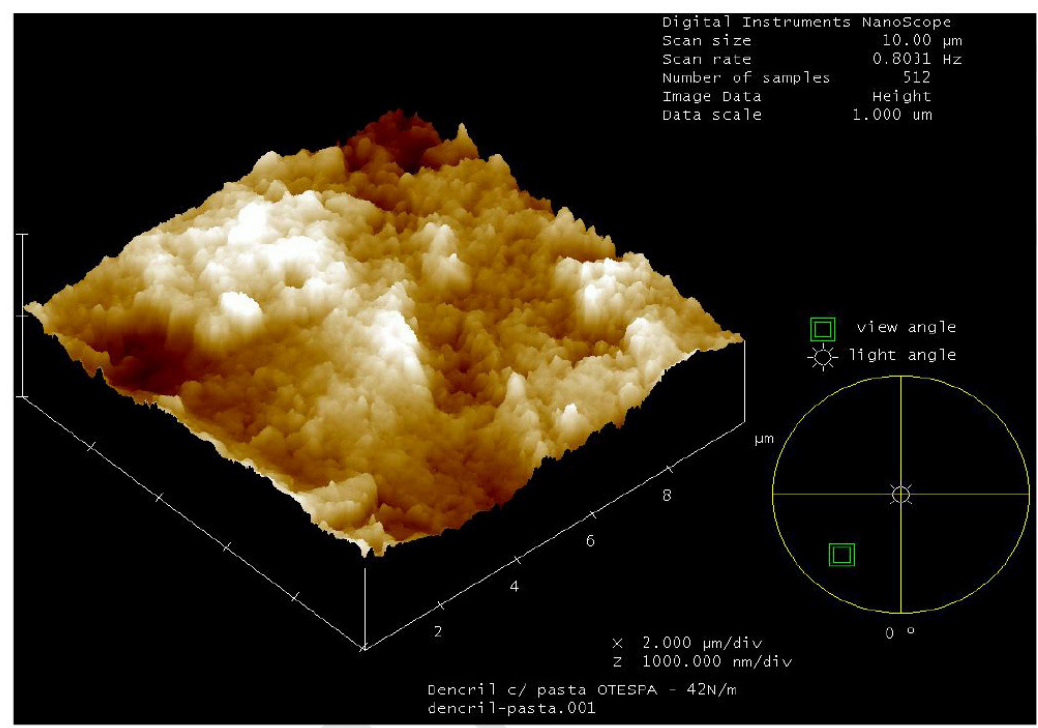

Figura 11. GXII - Dencrilay com pasta e feltro Fonte: elaboração própria

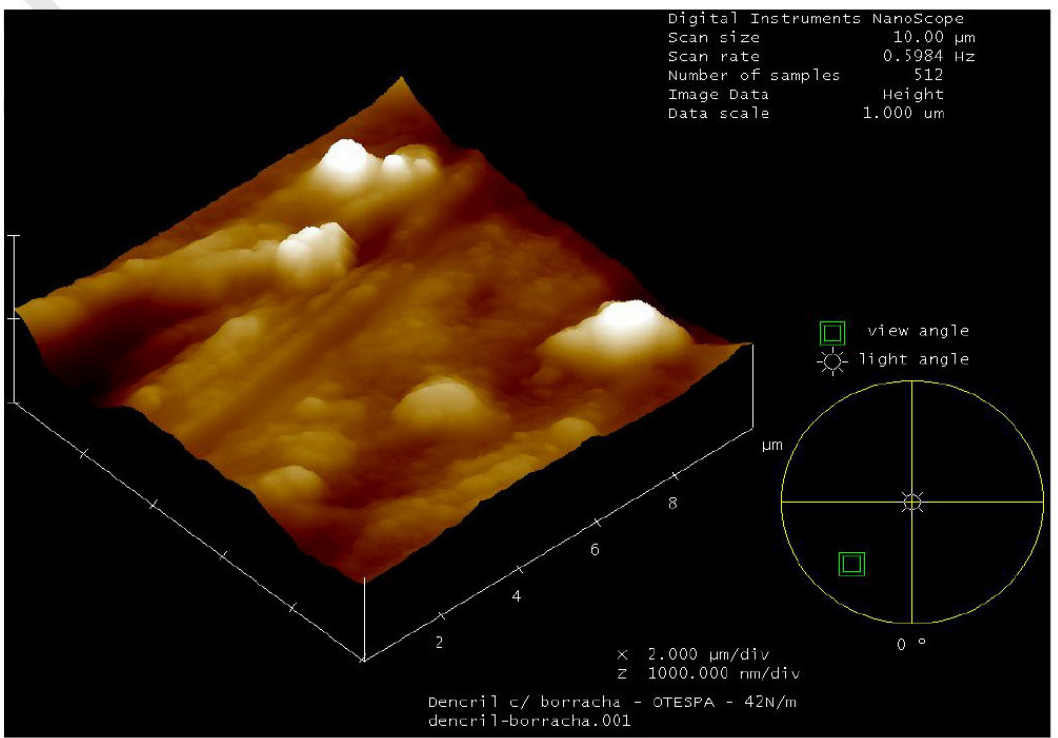

Figura 12: GXIII - Dencrilay com borracha

Fonte: elaboração própria 

João Batista Novaes Júnior, Amália Moreno, Elissa Talma, Ivan Barreiros Doche, Frederico dos Reis Goyatá

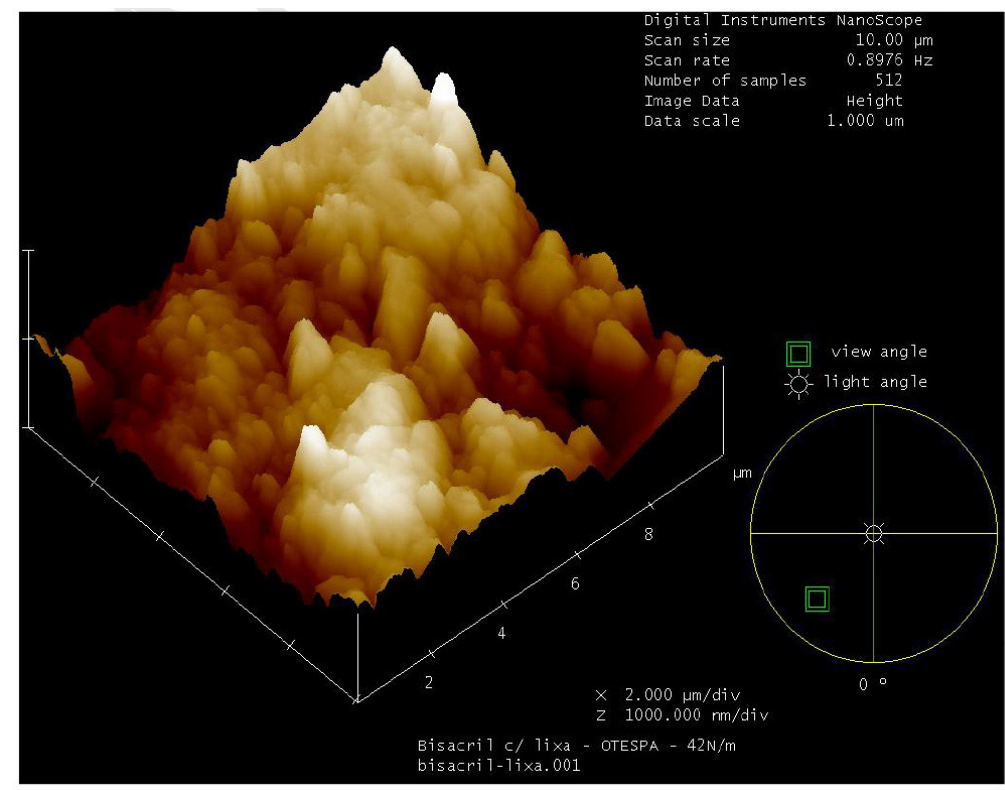

Figura 13.

Fonte: elaboração própria

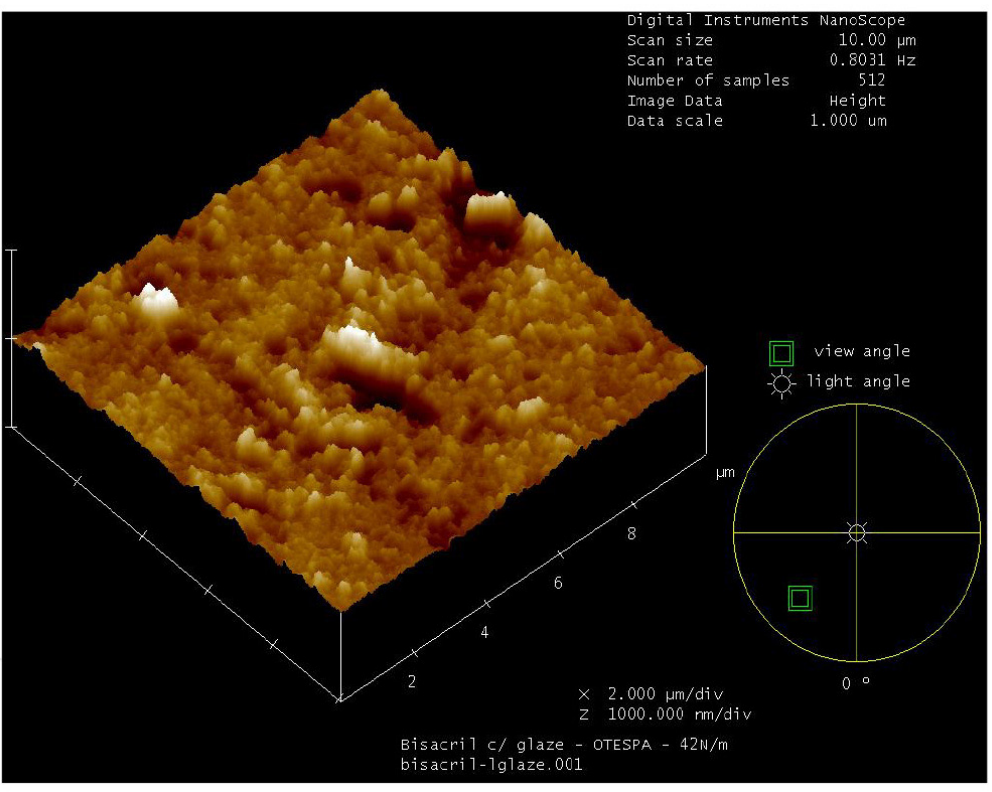

Figura 14.

Fonte: elaboração própria 
Avaliação da Topografia de Superfície e Microdureza de Resinas Acrílicas e uma Resina Bisacrílica Submetidas a Diferentes Técnicas de Polimento

\section{Discussão}

Este estudo demonstrou o efeito de diferentes técnicas de polimento com relação à microdureza e a rugosidade superficial de resinas acrílicas autopolimerizáveis e uma resina bisacrílica. Desta maneira, estudarmos e observarmos a lisura de superfície dos materiais resinosos é de extrema importância na prática clínica, promovendo maior integridade marginas nas restaurações provisórias e saúde ao periodonto.

Deste modo, confirma-se a teoria apresentada por Quirynen et al (5), que afirmam que a rugosidade das superfícies facilita o acúmulo de placa bacteriana. Além deste trabalho, Rego et al (4) puderam observar com os resultados obtidos em seus experimentos que os métodos de tratamento superficial promoveram uma menor adesão bacteriana.

Barbosa et al (20), em seus experimentos, não observaram diferença estatística e nem numérica em seus estudos quanto ao acabamento e polimento de superfície de cinco resinas acrílicas, mas no presente estudo foi possível observar diferenças estatísticas e numéricas para a resina acrílica Dencrilay em relação às outras resinas acrílicas utilizadas no mesmo estudo.

Amicrodureza deumaresinaéumimportante fatora serlevado emconsideração, já que o desgaste a abrasão promove maior área de contato e, assim, leva ao acúmulo de bactérias. Neisser et al (16), pontuaram diversos comportamentos para cada tipo de resina avaliada, e quanto maior a dureza menor a área de contato. Concordando com esses resultados, este trabalho observou diversos comportamentos de microdureza, sendo que a resina acrílica Duralay com borracha abrasiva obteve maior valor de microdureza.

De acordo com o estudo de Sen et al (18) e Barbosa et al (1), as resinas bisacrílicas não permitem um polimento superficial tão bom como o que se consegue obter com as tradicionais resinas acrílicas. Já no presente estudo, a resina bisacrílica Proviplast obteve a rugosidade superficial menor que todas as resinas acrílicas testadas, porém sua microdureza foi inferior às demais resinas devido à diferença na sua composição química se comparado às resinas acrílicas.

Com isso, pode-se afirmar que a resina bisacrílica Proviplast pode ser indicada para restaurações provisórias em dentes anteriores, por possuir bom polimento superficial, conferindo assim um maior brilho, não sendo indicada para dentes posteriores pelo baixo valor de microdureza comparado às resinas acrílicas. Em relação às resinas acrílicas podemos observar que a resina Dencrilay e a resina Duralay obtiveram bons resultados de rugosidade e microdureza, associado ao polimento com borracha abrasiva, sendo assim indicado tanto para dentes posteriores quanto inferiores. 


\section{Conclusões}

Todas as técnicas de polimento realizadas foram eficazes na redução do valor da rugosidade de superfície. A resina bisacrílica Proviplast com glaze obteve o menor valor de rugosidade de superfície entre todas as resinas utilizadas no estudo, mesmo que sua microdureza tenha sido inferior às demais resinas investigadas.

Ao final da elaboração das restaurações provisórias em resina acrílica ou bisacrílicas, é muito importante o cirurgião dentista se esmerar para obter o melhor polimento a fim de garantir uma maior lisura de superfície e como consequência prover maior saúde ao periodonto.

\section{Referências}

1. Barbosa DGO, Montenegro AC, Duarte JLP. Avaliação da rugosidade superficial de três resinas acrílicas para restauração provisória submetidas a diferentes métodos de polimento. Rev Bras Odontol. 2013; 70(2): 152-5. doi: http://dx.doi.org/10.18363/rbo.

2. Rutkūnas V, Sabaliauskas V, Mizutani H. Effects of different food colorants and polishing techniques on color stability of provisional prosthetic materials. Dent Mater J. 2010; 29(2): 167-76. doi: http://dx.doi.org/10.1590/S0103-64402011000500003.

3. Braun KO, Pellegrin DZ, Coradini L, May LG. Análise da rugosidade superficial de resinas acrílicas para coroas provisórias submetidas a diferentes tipos de polimento. RFO UPF. 2006; 11(2): 41-44. doi: https://doi.org/10.5335/rfo.

4. Rego MRM, Kitahara FMF, Santiago LC. Acrylic resin: relation between surface treatment and bacterial adhesion. Cienc Odontol Bras. 2005; 8(3): 92-98. doi: http://dx.doi.org/10.1590/21776709.21.4.012-013.edt.

5. Quirynen M, Bollen CM. The influence of surface roughness and surface-free energy on supra- and subgingival plaque formation in man. A review of the literature. J Clin Periodontol. 1995; 22 (1): 1-14.

6. Serra G, Morais LS, Elias CN. Surface morphology changes of acrylic resins during finishing and polishing phases. Dental Press J Orthod. 2013; 18(6):26-30. doi:http://dx.doi.org/10.1590/ S2176-94512013000600005. 
Avaliação da Topografia de Superfície e Microdureza de Resinas Acrílicas e uma Resina Bisacrílica Submetidas a Diferentes Técnicas de Polimento

7. Yap AUJ, Sau CW, Lye KW. Effects of finishing/polishing time on surface characteristics of tooth-coloured restoratives. J Oral Rehabil. 1998; 25(6): 456-61.

8. Cardoso C, Araújo A, Lopes GC, Araújo É, Baratieri LN. Efeito da refrigeração na rugosidade superficial e dureza das resinas compostas durante o procedimento de polimento. Rev Dent Press Estet. 2006; 3(1): 20-26.

9. Pontes AP, Mainieri ÉT, Pacheco JFM, Martins JL, Shinkai RAS, Mainieri VC. Rugosidade superficial de compósitos microparticulados e nanoparticulados após acabamento e polimento. RGO - Rev Gaúcha Odontol. 2009; 57(2): 179-82. doi: https://doi.org/10.11606/issn.2357-8041. clrd.2015.83527.

10. Corsalini M, Boccaccio A, Lamberti L, Pappalettere C, Catapano S, Carossa S. Analysis of the performance of a standardized method for the polishing of methacrylic resins. Open Dent J. 2009; 3: 233-40.doi: 10.2174/1874210600903010233.

11. Cazzaniga G, Ottobelli M, Ionescu A, Garcia-Godoy f, Brambilla E. Surface properties of resin-based composite materials and biofilm formation: a review of the current literature. Am J Dent. 2015; 28(6): 311-20. PMID: 26846036.

12. Bayraktar Y, Ercan E, Hamidi MM, Colak H. One-year clinical evaluation of different types of bulk-fill composites. J Invest Clin Dent. 2017; 8(2): 1-9.doi: 10.1111/jicd.12210.

13. Gharechahi M, Moosavi H, Forghani M. Effect of surface roughness and materials composition on biofilm formation. J Biomater Nanobiotechnol. 2012; 3: 541-46. doi: http://dx.doi. org/10.4236/jbnb.2012.324056.

14. Ikeda M, Matin K, Nikaido T, Foxton RM, Tagami J. Effect of surface characteristics on adherence of S. mutans biofilms to indirect resin composites. Dent Mater. 2007; 26(6): 915-23. doi: 10.1111/j.1600-0722.2012.00983.

15. Orsi IA, AndradeVG, Bonato OS, Raimundo LB, Herzog DS, BorieE. Glutaraldehyde release from heat-polymerized acrylic resins after disinfection and chemical and mechanical polishing. Braz Dent J. 2011; 22(6): 490-96. doi: http://dx.doi.org/10.1590/S0103-64402011000600009.

16. Neisser MP, Olivieri KAN. Avaliação da resistência ao impacto e dureza de resinas acrílicas termicamente ativadas para base de próteses totais. Braz Dent Sci. 2010; 4(2): 35-42. doi: http://dx.doi.org/10.14295/bds.2001.v4i2.115. 
17. Ulusoy M, Ulusoy N, Aydin AK. An evaluation of polishing techniques on surface roughness of acrylic resins. J Prosthet Dent. 1986; 56(1): 107-12. doi: http://dx.doi. org/10.1016/0022-3913(86)90292-1.

18. Sen D, Goller G, Issever H. The effect of two polishing pastes on the surface roughness of bisacryl composite and methacrylate - based resins. J Prosthet Dent. 2002; 88(5): 527-32. doi: 10.1067/mpr.2002.129335.

19. Oliveira JR, Paradella TC, Rego MA, Koga-ito CY, Jorge AOC. Avaliação da aderência microbiana e rugosidade superficial de resina acrílica quimicamente ativada após ciclagem com diferentes soluções desinfetantes. Cienc Odontol Bras. 2007; 10(2): 54-60.

20. Barbosa GKS, Zavanelli AC, Guilherme AS, Zavanelli RA. Effect of finishing and polishing techniques on the surface roughness of resin acrylic used one temporary restorations. Cienc Odontol Bras.2009; 12(1):15-22. doi:http://dx.doi.org/10.1590/1981-86372017000200003241.

21. Seabra EJG, Lima IPC, Matsuno M, Paiva ACS. Rugosidade superficial da resina acrílica frente a quatro diferentes técnicas de polimento. RGO - Rev Gaúcha Odontol. 2011; 59(1): 45-50.

22. Giacomelli L, Derchi G, Frustaci A, Orlando B, Covani U, Barone A, Santis D, Chiappelli F. Surface roughness of commercial composites after different polishing protocols: an analisys with Atomic ForceMicroscopy. Open DentJ.2010;15(4):191-94.doi:10.2174/1874210601004010191.

23. Da Costa J, Ferracane J, Paravina RD, Mazur RF, Roeder L. The effect of different polishing systems on surface roughness and gloss of various resin composites. J Esthet Restor Dent. 2007; 19(4): 214-24. doi: http://dx.doi.org/10.1590/S1678-77572009000100005.

24. Antonson SA, Yazici AR, Kilinc E, Antonson DE, Hardigan PC. Comparison of different finishing/polishing systems on surface roughness and gloss of resin composites. J Dent. 2011; 39(1): 9-17.doi: 10.1016/j.jdent.2011.01.00.

25. Montanaro L, Campoccia D, Rizzi S, Donati ME, Breschi L, Prati C, Arciola CR. Evaluation of bacterial adhesion of Streptococcus mutans on dental restorative materials. Biomaterials. 2004; 25(18): 4457-63. doi: 10.1016/j.biomaterials.

26. Ionescu A, Brambilla E, Wastl DS, Giessibl FJ, Cazzaniga G, Schneider-Feyrer S, Hahnel S. Influence of matrix and filler fraction on biofilm formation on the surface of experimental resin-based composites. J Mater Sci Mater Med. 2015; 26(1): 1-7.doi: 10.1007/s10856-014-5372-4. 
27. Santos AM, Commar BC, Bonatto LR, Silva EVF, Sônego MV, Rangel EC, Pesqueira AA, Goiato MC. Surface characterization of polymers used in fabrication of interim prostheses after treatment with photopolymerized glaze. Mater Sci Eng C. 2017; 71: 755-63.doi: 10.1016/j. msec.2016.10.059

28. Liberato FL, Padoan AC, Morgado GL, Coelho LVBF. Avaliação da rugosidade superficial de uma resina composta após polimento com discos de lixa e pontas siliconadas. Rev Biocien. 2004; 10(1-2): 51-54.

29. Scheibe KGBA, Almeida KGB, Medeiros IS, Costa JF, Alves CMC. Effect of different polishing systems on the surface roughness of microhybrid composites. J Appl Oral Sci. 2009; 17(1): 21-6. doi: http://dx.doi.org/10.1590/S1678-77572009000100005.

30. Cakan U, Kara HB. Effect of liquid polishing materials on the stainability of bisacryl interim restorative material in vitro. J Prosthet Dent. 2015; 113(5): 475-79.

31. Rahal JS, Mesquita MF, Henriques GE, Nóbilo MA. Surface roughness of acrylic resins submitted to mechanical and chemical polishing. J Oral Rehabil. 2004; 31(11): 1075-9. doi: 10.1111/j.1365-2842.2004.01344.x.

32. Zanghellini G, Rheinberg V, Arends J. Quantification of deposits in the oral cavity on various materials after a 1-year period. J Prosthet Dent. 1993; 70(5): 414-2. PMID:8254543.

33. Gotusso MJ. Sorption of heat-cured acrylic resins chemically polished. J Dent Res.1969; 48: $1072-8$.

34. Neves AC, Vilela LC. Avaliação da rugosidade da superfície da resina acrílica termopolimerizável incolor após acabamento e polimento convencionais e após a aplicação de um verniz específico para acabamento de resina acrílica. PGR: Pós-Grad Rev Fac Odontol. 1999; 2(2): 15-21. doi: 10.14295/bds.1999.v2i2.44. 